\title{
Michel Brix, Nerval, Glanes et miettes de presse
}

\section{Lise Sabourin}

\section{(2) OpenEdition}

\section{Journals}

\section{Édition électronique}

URL : http://journals.openedition.org/studifrancesi/4423

DOI : 10.4000/studifrancesi.4423

ISSN : 2427-5856

\section{Éditeur}

Rosenberg \& Sellier

\section{Édition imprimée}

Date de publication : 1 septembre 2016

Pagination : $350-351$

ISSN : 0039-2944

\section{Référence électronique}

Lise Sabourin, « Michel Brix, Nerval, Glanes et miettes de presse », Studi Francesi [En ligne], 179 (LX| II) |

2016, mis en ligne le 01 septembre 2016, consulté le 18 septembre 2020. URL : http://

journals.openedition.org/studifrancesi/4423; DOI : https://doi.org/10.4000/studifrancesi.4423

\section{Ce document a été généré automatiquement le 18 septembre 2020}

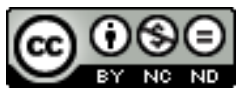

Studi Francesi è distribuita con Licenza Creative Commons Attribuzione - Non commerciale - Non opere derivate 4.0 Internazionale. 


\title{
Michel Brix, Nerval, Glanes et miettes de presse
}

\author{
Lise Sabourin
}

\section{RÉFÉRENCE}

MICHEL BRIX, Nerval, Glanes et miettes de presse, Paris, Honoré Champion, 2013, 308 pp.

1 Michel Brix rassemble en ce volume sous le titre Nerval, Glanes et miettes de presse, toute une série, parfois remaniée, de ses articles, pour la plupart brefs, donnant des informations sur la vie et l'œuvre de Nerval, issus de ses enquêtes dans les journaux et périodiques du $\mathrm{XIX}^{\mathrm{e}}$ siècle.

2 Nerval, Gérard, Beuglant, Aloysius, Fritez et Cie: Gérard Labrunie et ses doubles (pp. 9-26) parcourt tous les pseudonymes, plus ou moins consciemment employés, qu'a utilisés l'écrivain: outre Beuglant, Aloysius en 1838-40, Fritz en 1839-40, Gérard l'emporte jusqu'en 1840, à côté de noms d'auteurs réels dont il assumait ainsi des écrits prétendument apocryphes; mais Gérard de Nerval s'impose progressivement à partir de 1836, avec ses variantes G. de Nerval ou Gérard de N. Autant de façons d'échapper au patronyme paternel et d'user en quasi anagramme de celui d'une mère tôt disparue.

3 Nerval, Janin et l'héritage de Nodier (pp. 27-68) enquête sur ses relations avec le peu amène prince des critiques, malgré son "optimisme heureux" d'homme à succès. Janin, après s'être montré assez laudateur sur Léo Buckart, est l'auteur du fameux article de 1841 qui attache l'étiquette de «folie » à Nerval en mentionnant son internement du moment chez le docteur Blanche, ce qu'évitera Dumas en circonstances similaires ultérieures. Nerval, tout en revendiquant l'héritage fantastique de Nodier et de Cazotte, se révolte cependant peu contre cette stigmatisation, préférant affirmer sa quête de rêve et d'idéal face à l'inexpérience du critique en tels domaines...

4 Du neuf sur "Pandora" (pp. 69-74) signale l'article d'Amédée Achard dans «L'Assemblée nationale» du 23 septembre 1849 éclairant la présence de Marie Pleyel à Vienne durant l'hiver 1839-40. 
Nerval et «L'Événement» (pp. 75-91) retrace l'usage qu'y fait Vacquerie de La Main de gloire pour évoquer métaphoriquement Musset et le portrait de Nerval brossé par Mirecourt dans ses Contemporains.

Nerval et «Le Mousquetaire» (pp. 83-109) rappelle que parurent dans le journal de Dumas «Octavie», le début de Pandora et «El Desdichado» et recense d'autres mentions à propos des Filles $d u f e u$, de Lorely, ainsi que des détails sur la mort, les funérailles et un portrait posthume de Nerval par Houssaye.

$7 \quad$ Nerval "nègre" de Houssaye? (pp. 111-117): telle est la question qu'il est permis de se poser à lire les autographes possédés par Houssaye au décès de Nerval, qui pourrait bien lui avoir prêté sa plume pour son Histoire de la peinture flamande et hollandaise. Inversement, l'on peut aussi se demander si Nerval est [bien] l'auteur de "Paradoxe et vérité" (pp. 119-131), cet ensemble de 29 pensées parues dans «L'Artiste» en juin 1844, réédités dans «La Presse» en septembre 1865, puis dans «L'Artiste» en novembre 1877 et dans «Le Livre» en 1883: la contestation d'attribution lancée par Alphonse Duchesne dans «Le Figaro» en 1865 pourrait bien révéler les "menteries" du directeur de "L'Artiste», mais le cas restant douteux, on ne peut vraiment les exclure de l'œuvre de Nerval.

9 Nerval et Eugène Scribe (pp.133-140) présente une querelle indigne lancée par Philibert Audebrand dans «La Gazette de Paris» en 1859 à propos du procès fait par Scribe au décorateur Héreau et un compte rendu retrouvé sur Judith et la loge d'Opéra, nouvelle de 1837, utilisée par Bayard et Dumanoir pour leur Judith comme par Scribe pour sa Figurante.

10 Sur les "Voyages à pied" (pp.141-145) fournit une reproduction oubliée d'un dizain macaronique adressé à Dumas depuis l'Allemagne durant l'été 1838, inséré dans Lorely puis dans les Voyages de 1840.

11 D'un carnaval à l'autre (pp. 147-158) narre comment Nerval, après un article assez négatif sur les masques accompagnant «Le Bœuf gras» dans «L'Artiste» en février 1845 en réponse à «La Démocratie pacifique» fit en 1850 un éloge paradoxalement «légumiste» de la promenade de la mascotte des bouchers déguisés d'après ses Monténégrins représentés à l'Opéra-Comique en 1849 .

12 Sur "Une nuit blanche" (pp.159-177) relate comment Nerval condensa en une folie en un acte une ample fantasmagorie signée avec ses collaborateurs sous le masque de Bosquillon père et fils: outre le compte rendu de Gautier dans «La Presse» de février 1850, sans doute écrit par Nerval, cette contribution fournit tous les éléments de la polémique déclenchée par sa représentation à l'Odéon.

13 Sur "Pruneau de Tours" (pp. 179-183) informe sur le masque également gardé par Nerval à propos de ce vaudeville en un acte joué au Gymnase en mai 1850, auquel il fit allusion dans «La Presse» de septembre pour l'avoir vu à Bruxelles en août, sans révéler la part des droits qu'il touchait aux côtés de frères Cogniard, signataires officiels.

Deux billets retrouvés à Victor Lecou et à Adrien Dauzats (pp. 185-192) confirment ses relations avec l'éditeur des Illuminés et avec ce peintre orientaliste.

Un exemplaire dédicacé des "Filles du feu" et une copie d'«El Desdichado» (pp. 193-196) se trouvent dans les lettres redécouvertes à Francis Wey, attestant pour le premier de sa proximité avec son épouse, et fournissant pour la seconde quelques variantes non autographes. 

(pp. 233-236) présentes dans la «Revue des feuilletons dramatiques» d'Achille Kuhnholtz en 1845-46, ainsi que les articles de Nerval et Gautier à «L'Estafette» de 1838 à 1851 (pp. 237-246).

21 La fameuse narration de La Harpe Sur la prédiction de Cazotte (pp. 241-247) perd de son caractère prophétique quand on sait que Petitot omit de publier un paragraphe essentiel sur son statut fictif lors de la réédition qui la rendit célèbre en 1816-17.

L'origine de la photographie prise par Nadar junior est éclairée dans Postérité judiciaire de Nerval [lors du] procès Tournachon-Houssaye (pp. 249-251).

Quelques Brèves (pp. 253-258), sur la publication du Nouveau Genre et des «Fêtes de mai en Hollande», des articles de Nerval dans «Le Phare industriel» et «Le Journal des coiffeurs» ou ses relations avec la poste, viennent clore ce volume, avant la publication en Appendices du Pruneau de Tours (pp. 254-287) et de l'article de Paulin Limayrac sur Nerval dans «La Presse» du 31 juillet 1853.

24 Autant d'articles qui fournissent aux nervaliens maints renseignements utiles, ainsi réunis par un spécialiste reconnu pour ses autres publications, fort nombreuses, sur cet auteur depuis 1986. 